\title{
THE VISUALIZATION OF THE CHINESE ECONOMY FROM A MULTI-DIMENSIONAL PERSPECTIVE: 1979-2009
}

\author{
Mario Arturo Ruiz Estrada and Emile Kok-Kheng Yeoh
}

\section{Introduction}

In the study of complex economic phenomena, it is common to observe the application of different statistical methods to analyze historical data (database) or to generate forecasts under the application of different econometrics models. This is based on the use of sophisticated and powerful computer software to run a large number of variables (multi-variable), functions and equations simultaneously. But the graphical modeling applied in statistics methods and econometric models until today continue to be displayed on 2-dimensional graphs. This research argues that 2-dimensional graphs cannot visualize a large number of variables (multi-variables), functions and equations simultaneously in the same graphical space.

In contrast, we suggest the application of inter-linkage coordinate space and graphical animation that facilitates the visualization of complex economic phenomena in the same graphical space in real time. ${ }^{1}$ Hence, the use of inter-linkage coordinate space with different statistical methods and econometrics models can facilitate the visualization of large number of databases, or different results, on the same graphical space. To apply inter-linkage coordinate space and multi-dimensional graphical animation, we need to assume that the market is formed by a group of sub-markets and that all these sub-markets are moving in real time. These sub-markets are the goods sub-market, money sub-market, social sub-market, financial sub-market, international trade sub-market, labor sub-market, government sub-market, transport \& energy submarket and technological sub-market (see Table 2 and Figure 1). Each sub-market has a large number of windows refraction (or quadrants), and each window refraction (or quadrant) is formed by its $X$-axis which represents time (days, weeks, months, years and decades) and its $Y$-axis which represents the main variable in analysis, based on the use of growth rates respectively. Each sub-market shows four, five or an infinite number of windows refraction, according to our research priorities (see Table 1); at the same time, these windows refraction show different relationship(s) and different partial times.

The idea of time and space in this paper is totally different from the traditional view of time. It is assumed that the market is formed by a large number of sub-markets that are moving all the time at different speeds of time under the application of the Omnia

1 Ruiz Estrada, M.A., 'Econographicology', International Journal of Economics Research (IJER), Vol. 4 No. 1, 2007, pp.75-86. 
Mobilis assumption (everything is moving). ${ }^{2}$ Each sub-market is formed by a large number of windows refraction (or quadrants) that are also moving at different speeds of time. This paper proposes to divide time into four types: general time (universal time), evolutionary time (future time), partial time (present time) and constant time (past time). The first assumption to support that different types of time exist is that any economic phenomenon is multi-dimensional and therefore each of its dimension(s) develops different speeds of time.

Table 1: Sub-Markets and Windows Refraction

\begin{tabular}{|c|c|c|}
\hline Sub-Market 1: & Sub-Market 2: & Sub-Market 3: \\
\hline Windows Refraction: & Windows Refraction: & Windows Refraction: \\
\hline Windows Refraction 1 : & Windows Refraction 1: & Windows Refraction 1: \\
\hline Windows Refraction 2: & Windows Refraction 2: & Windows Refraction 2: \\
\hline Windows Refraction 3: & Windows Refraction 3: & Windows Refraction 3: \\
\hline & & Windows Refraction 4: \\
\hline & . & . \\
\hline Windows Refraction $\infty$ : & Windows Refraction $\infty$ : & Windows Refraction $\infty$ : \\
\hline Sub-Market 4: & Sub-Market 5: & Sub-Market 6: \\
\hline Windows Refraction: & Windows Refraction: & Windows Refraction: \\
\hline Windows Refraction 1: & Windows Refraction 1: & Windows Refraction 1: \\
\hline Windows Refraction 2: & Windows Refraction 2: & Windows Refraction 2: \\
\hline Windows Refraction 3: & Windows Refraction 3: & Windows Refraction 3: \\
\hline & & . \\
\hline . & . & . \\
\hline & . & . \\
\hline Windows Refraction $\infty$ : & Windows Refraction $\infty$ : & Windows Refraction $\infty$ : \\
\hline Sub-Market 7: & Sub-Market 8: & Sub-Market $\infty:$ \\
\hline Windows Refraction: & Windows Refraction: & Windows Refraction: \\
\hline Windows Refraction 1: & Windows Refraction 1: & Windows Refraction 1: \\
\hline Windows Refraction 2: & Windows Refraction 2: & Windows Refraction 2: \\
\hline Windows Refraction 3: & Windows Refraction 3: & Windows Refraction 3: \\
\hline & & 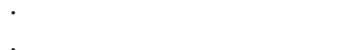 \\
\hline & & \\
\hline Windows Refraction $\infty$ : & Windows Refraction $\infty$ : & Windows Refraction $\infty$ : \\
\hline
\end{tabular}

2 Ruiz Estrada, M.A., Yap, S.F. and Nagaraj, S., 'Beyond the Ceteris Paribus Assumption: Modeling Demand and Supply Assuming Omnia Mobilis', International Journal of Economic Research (IJER), Vol. 5 No. 2, 2008, pp. 185-194. 
For the purposes of this research, we would like to define the different type(s) of times. First, partial time shows different events through time and space of any economic phenomenon according to unexpected natural and uncontrolled events. Second, partial time always becomes constant time: this means that every second, minute, hour, day, week, month and year that passes becomes a constant time (past time). Third, evolutionary time (future time) is always moving under constant chaos and imbalance all the time. Fourth, general time is the synchronization of an infinite number of partial times running into an infinite windows refraction or an infinite number of sub-markets.

We argue that the application of inter-linkage coordinate space and multidimensional graphical animation facilitates the understanding of the behavior and trends of complex economic phenomena within the same graphical space. The inter-linkage coordinate space and multi-dimensional graphical animation can generate a global visual effect to observe the behavior of any economy as a whole; at the same time, this alternative multi-dimensional graphical modeling can generate a "real time effect" under the application of graphical computer animation based on the construction of a large number of slides that are joined together into the assembly and production of a video. It is possible to observe different variables simultaneously in constant movement. This multi-dimensional graphical technique can make it possible to observe the failures of different sub-markets in the same graphical space, and at the same time, the generation of suitable policies to solve these failures in different sub-markets in moments of economic recession or economic crisis.

\section{Analysis of the Chinese Economy from a Multidimensional Perspective (1979-2009)}

This paper presents the development of the Chinese economy from 1979 to 2009 in a single graph; the same graph makes it possible to visualize nine sub-markets and forty windows refraction interacting in the same graphical space. The three decades covered by this graph constitute a remarkable period during which China has experienced uninterrupted growth at recorded rates often exceeding 10 per cent annually, leading to rising GDP per capita and accompanied by outstanding reduction of poverty. Since launching the policy of "open and reform" in the late 1970s with the overall aim to encourage the modernization of the Chinese economy while maintaining an at least nominally socialist structure, China has achieved levels of economic growth that were nothing less than miraculous. From 1978 to 2006, the real gross domestic product (GDP) has been growing by about 9.6 per cent annually and has continued to sustain its robustness till today - this is a growth that has continued remarkably uninterrupted, even during the adverse events such as the Asian financial crisis of 1997-1998 and the SARS outbreak of 2003. The growth of China's income per capita is much faster than that of any other region in the world. ${ }^{3}$ Hence, the profound changes experienced by China in the recent decades are due both to the dramatic economic reform launched by Deng

3 Remarks by Timothy D. Adams, US treasury under-secretary for international affairs, to the Asia Society and Houston Society of Financial Analysts, Houston, Texas, on 7th April $2006<$ http:/ / www. ustreas.gov/press/releases/js4172.htm>. Per capita income in this fastest growing economy in the world was observed to double every ten years, faster than any country in recent history (see address to Asian Development Bank's International Workshop on Regional Development and Fiscal Policy, 2000 <http://www.adb.org/Documents/Speeches/2000/ms2000023.asp>; see also Hu, Hu and Chang, 2003). 
Xiaoping and country's single-mindedness to bring to fruition her "third revolution". Under this open-door policy, the Chinese economy has gradually reduced the scope of mandatory planning which gave way to greater decentralization and the adoption of a free market system. Externally, with a large and fast growing market, China had become the global buyer of goods and services from other countries especially the member countries of ASEAN. This is because of the need for raw materials to sustain the rapid growth of the country's economy especially in the manufacturing sector. Besides, exports have been growing at twice the world average, backed by strategies of export subsidies and trade reform and advantages of competitive labour cost and highly skilled labour.

While the economic and political rise of China has been astounding, not all regions in this vast country enjoy equally the fruit of growth. While the country's growth record since the start of economic reforms in 1978 has been impressive, the rapid pace of growth has contributed to substantial differences in growth rates and levels of income per capita across different regions of the country. China's inequality has indeed risen alarmingly as a whole, within urban and rural areas, between urban and rural areas and across provinces and regions. The problem of poverty in China has a strong regional dimension, and high poverty rate in China does not only lead to regional disparity, but also to other social problems. Regions with high poverty rate normally face low infrastructure developments such as those related to road condition, water supply, electricity supply and telecommunication services. Meanwhile, according to official data, approximately 90 per cent of the China's populations who live in absolute poverty are found in the western region. ${ }^{4}$ This could be attributed to the crucial regional dimension in the country's development policies. The open-door policy and coastal development strategy during the 1980s and 1990s which favoured the coastal areas have increased interregional inequality significantly. In this regard, even international trade has revealed the distinct inequalities between the coastal region and the inland region, with the former being much more export-oriented than the latter. Studies have contended that for any given level of natural or human capital, the greater the inequality, the higher the poverty that can be expected. Furthermore, inequality is also seen to affect long-term economic growth, although there is no consensus on the direction of the effect. If inequality affects growth positively, it is possible that the poverty rate can be reduced; otherwise, a country could be saddled with the unenviable triad correlated problems of rising inequality, sluggish growth and worsening poverty.

However, for the purposes of this research, we will not go too deeply in the analysis of the Chinese economy; we will explore it only to display the Chinese economy within a multi-dimensional coordinate space under the use of different databases in different sub-markets (windows refraction). The application of the multi-dimensional coordinate space method offers an alternative multi-dimensional graphical modeling technique for economists, policy makers, students and academics. This graph has 3,200 values plotted into forty windows refraction located within nine sub-markets. These sub-markets are comprised of the goods sub-market, money sub-market, social sub-market, financial sub-market, international trade sub-market, labor sub-market, government sub-market, transport \& energy sub-market and technological sub-market (see Table 2 and Figure 1). ${ }^{5}$

4 Beijing Review, 10 April 2000, pp. 14.

5 Ruiz Estrada, M.A., 'Is the Market in a Dynamic Imbalance State?' International Journal of Economic Research (IJER),Vol. 5, No. 2, 2008, pp. 239-250. 


\section{Conclusion}

This paper conclude that the application of multi-dimensional physical spaces can offer to statistics and econometrics models an alternative multi-dimensional graphical modeling approach to visualize possible large number of database and results on the same graphical space.

Table 2 Sub-Markets and Windows Refraction: The Chinese Economy (1979-2009)

\begin{tabular}{|c|c|c|}
\hline Sub-Market 1: Goods Market & $\begin{array}{l}\text { Sub-Market 2: Money } \\
\text { Market }\end{array}$ & Sub-Market 3: Social Market \\
\hline $\begin{array}{l}\text { Windows Refraction: } \\
\text { Windows Refraction 1: GDP } \\
\text { Windows Refraction 2: Interest } \\
\text { Rate } \\
\text { Windows Refraction 3: } \\
\text { Investment } \\
\text { Windows Refraction 4: } \\
\text { Income }\end{array}$ & $\begin{array}{l}\text { Windows Refraction: } \\
\text { Windows Refraction 1: GDP } \\
\text { Windows Refraction 2: } \\
\text { Interest Rate } \\
\text { Windows Refraction 3: } \\
\text { Money: Supply and Demand } \\
\text { Windows Refraction 4: } \\
\text { Income }\end{array}$ & $\begin{array}{l}\text { Windows Refraction: } \\
\text { Windows Refraction 1: GDP } \\
\text { Windows Refraction 2: } \\
\text { Education } \\
\text { Windows Refraction 3: Low } \\
\text { Cost Housing } \\
\text { Windows Refraction 4: } \\
\text { Health Care }\end{array}$ \\
\hline $\begin{array}{l}\text { Sub-Market 4: Financial } \\
\text { Market } \\
\text { Windows Refraction: } \\
\text { Windows Refraction 1: GDP } \\
\text { Windows Refraction 2: FDI } \\
\text { Windows Refraction 3: Bonds } \\
\text { Windows Refraction 4: Stock } \\
\text { Market } \\
\text { Window Refraction 5: Real } \\
\text { Estate }\end{array}$ & $\begin{array}{l}\text { Sub-Market 5: International } \\
\text { Trade Market } \\
\text { Windows Refraction: } \\
\text { Windows Refraction 1: GDP } \\
\text { Windows Refraction 2: } \\
\text { Production } \\
\text { Windows Refraction 3: } \\
\text { Exports and } \\
\text { Imports } \\
\text { Windows Refraction 4: } \\
\text { Income }\end{array}$ & $\begin{array}{l}\text { Sub-Market 6: Labor Market } \\
\text { Windows Refraction: } \\
\text { Windows Refraction 1: GDP } \\
\text { Windows Refraction 2: } \\
\text { Investment Supply and } \\
\text { Windows Refraction 3: Labor: } \\
\text { Demand S S } \\
\text { Windows Refraction 4: } \\
\text { Unemployment } \\
\text { Window Refraction 5: Poverty }\end{array}$ \\
\hline 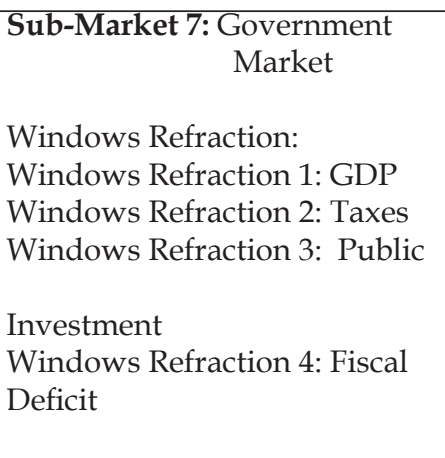 & $\begin{array}{l}\begin{array}{l}\text { Sub-Market 8: Technological } \\
\text { Market }\end{array} \\
\text { Windows Refraction: } \\
\text { Windows Refraction 1: GDP } \\
\text { Windows Refraction 2: } \\
\text { Investment } \\
\text { Windows Refraction 3: } \\
\text { Productivity } \\
\text { Windows Refraction 4: } \\
\text { Exports } \\
\text { Window Refraction 5: Income }\end{array}$ & $\begin{array}{l}\text { Sub-Market 9: Transport and } \\
\text { Energy Market } \\
\text { Windows Refraction: } \\
\text { Windows Refraction 1: GDP } \\
\text { Windows Refraction 2: Oil } \\
\text { Prices } \\
\text { Windows Refraction 3: } \\
\text { Energy Prices } \\
\text { Windows Refraction 4: } \\
\text { Transport Costs }\end{array}$ \\
\hline
\end{tabular}


Figure 1 The Chinese Economy from 1979-2009

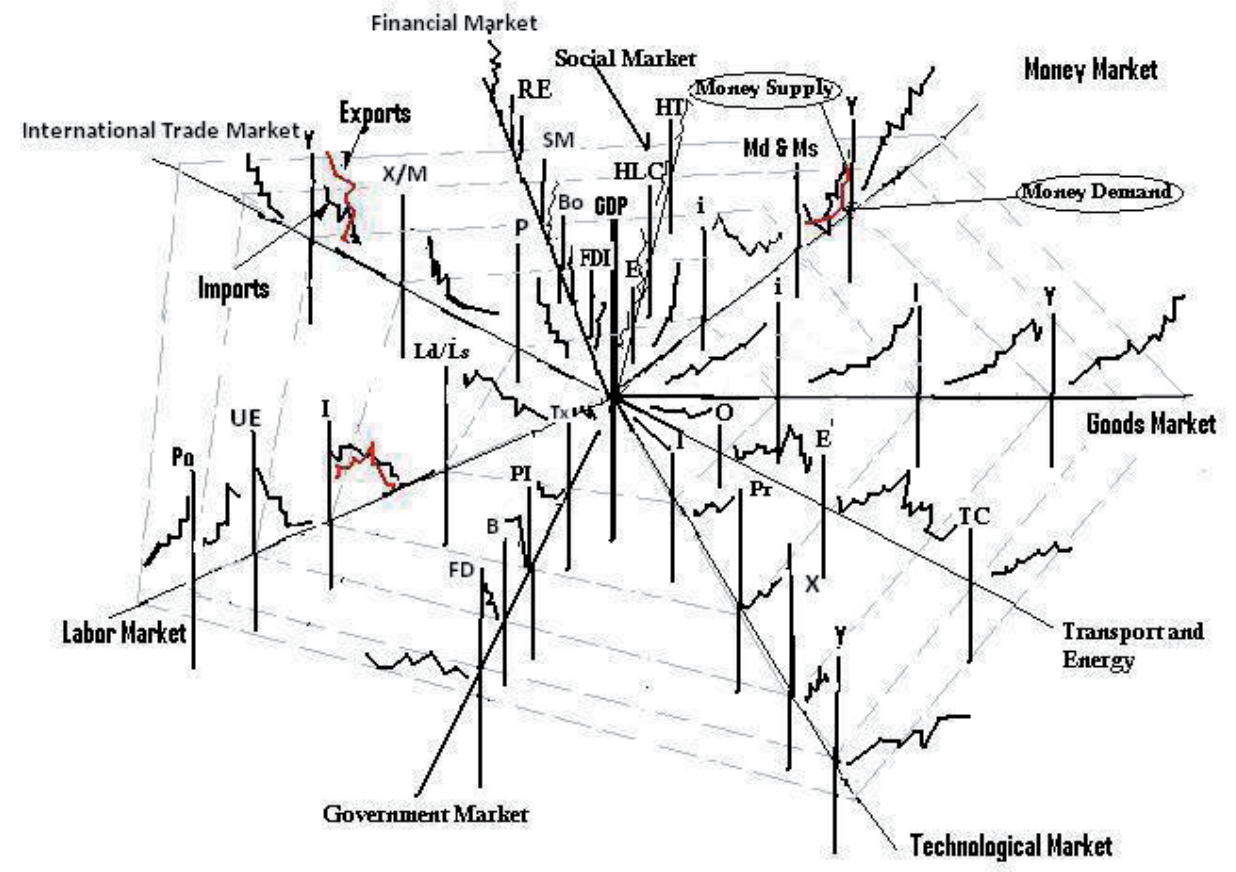

GDP: Gross Domestic Product

I: Investment

Md: Money Demand

FDI: Foreign Direct Investment

SM: Stock market

P: Production

M: Imports

Ls: Labor Supply

Po: Poverty

PI: Public Investment

FD: Fiscal Deficit

O: Oil Price

TC: Transport Costs

HLC: Low Cost Housing i: Interest Rates $\mathbf{Y}$ : Income Ms: Money Supply

Bo: Bonds

RE: Real Estate $\mathrm{X}$ : Exports

Ld: Labor Demand UE: Unemployment

Tx: Tax

B: Budget

Pr: Productivity

E': Energy Prices

E: Education

HT: Health Care

Sources: Asian Development Bank, General Information and Database Statistics, 2010, http://www.adb.org/; Ministry of Commerce of People's Republic of China (NCPRC), General Statistical Database, 2010, http:/ / english.mofcom.gov.cn/; National Bureau of Statistics of China (NBSC), General Statistical Database, 2010, http://www.stats.gov.cn/english/

\section{Concluding Remarks}

This paper confirms that the application of the inter-linkage coordinate space can offer an alternative multi-dimensional graphical modeling approach to visualize a large number of databases, econometrics and forecasting modeling results within the same graphical space and time. 